\title{
Improvement of Atrophic Acne Scar and Skin Complexity by Combination of Aqueous Human Placenta Extract and Mesenchymal Stem Cell Mesotherapy
}

\author{
Ruchee Phonchai',2, Pimjai Naigowit'2, Bunchob Ubonsaen ${ }^{3}$, Supansa Nilubol'2, \\ Supaluk Brameld ${ }^{4}$, Parinya Noisa ${ }^{*}$
}

${ }^{1}$ Laboratory of Cell-Based Assay and Innovations, Biotechnology, Suranaree University of Technology, Nakhon Ratchasima, Thailand ${ }^{2}$ LBM Stem Cell Research Unit, Life Balance Methodology Co., Ltd., Bangkok, Thailand

${ }^{3}$ Sangkhom Hospital, Nongkhai Provincial Health Office, Nongkhai, Thailand

${ }^{4}$ National Institute of Health, Ministry of Public Health, Nonthaburi, Thailand

Email: *ruchee.pc@gmail.com

How to cite this paper: Phonchai, R., Naigowit, P., Ubonsaen, B., Nilubol, S., Brameld, S. and Noisa, P. (2020) Improvement of Atrophic Acne Scar and Skin Complexity by Combination of Aqueous Human Placenta Extract and Mesenchymal Stem Cell Mesotherapy. Journal of Cosmetics, Dermatological Sciences and Applications, 10, 1-7.

https://doi.org/10.4236/jcdsa.2020.101001

Received: October 29, 2019

Accepted: January 19, 2020

Published: January 22, 2020

Copyright $\odot 2020$ by author(s) and Scientific Research Publishing Inc. This work is licensed under the Creative Commons Attribution International License (CC BY 4.0).

http://creativecommons.org/licenses/by/4.0/

\begin{abstract}
Atrophic scars, a permanent complication of severe acne, have negative effect on psychology in adolescent. The treatment of atrophic scar is depended on types of scar and it is difficult to improve by a single treatment. Mesenchymal stem cell is a scientific approval for surgery scar treatment and wound healing. We present a case report of female presented with atrophic acne scar distributed on both cheeks. The case aims to prove that the combination of MSCs and aqueous human placenta extract $\left(\mathrm{RGF}^{\circledR}\right)$ contained bioactive therapeutic molecules obviously promoted the improvement of skin scar to reach the optimal outcomes. We first found that MSCs-contained human placenta extract solution combination subcision improves the atrophic acne scar and skin complexity by enhancement of skin cell regeneration.
\end{abstract}

\section{Keywords}

Atrophic Scar, Mesenchymal Stem Cells, Human Placenta Extract, Mesotherapy, Skin, Regeneration

\section{Introduction}

Atrophic acne scar is often a permanent complication of acne vulgaris. It has a high prevalence in puberty and impacts on physical appearance and mental health [1]. The approach of atrophic acne scar is difficult and challenge for clini- 
cians. It varies depending on the types of acne scars and it has limitations of the treatment modalities in their ability to improve scars [2] [3]. Nowadays, there are many options for the treatment of atrophic acne scar, including chemical peeling, dermabrasion, laser, punch techniques, fat transplantation, and tissue augmenting agents, needling, subcision, and combination therapy [4]. Various modalities have been used to treat scars, but limited efficacy and problematic side effects have restricted their application.

Mesenchymal stem cells (MSCs) can be isolated from human umbilical cord [5]. The MSCs appear to be immune privileged and are therapeutic value for cell therapy [6]. MSCs pose a trophic effect on cell regeneration and tissue repair, which scientific approval reduced hypertrophic scars and atrophic acne scar [6] [7] [8] [9] [10]. MSCs seem to be an ideal source for tissue engineering application due to the lack of ethical concerns, high availability, and the increasing number of methods for isolation and expansion of such cell types [11].

Human placenta extract has utilized and widely used in clinical and cosmetic fields, and it possesses marked antioxidant activity [12]. Aqueous human placenta extract contains bioactive therapeutic molecules such as peptides, polypeptide, and DNA fragment, polydeoxyribonucleotides, proteins, vitamins, growth factors and hormones [13]. Placenta is a scientifically proven potent wound healer and skin problem [14] [15].

To optimally treat an atrophic acne scar, stem cell, and placenta therapy combination, the other approach is an option for the most satisfactory result. MSCs and human placenta extracts mesotherapy are the best treatment for skin cell regeneration and repairing tissue [16] [17] [18]. The stem cell may be useful for the best therapeutic strategies, whether it be single or combined therapy, in the treatment of atrophic acne scars while reducing or avoiding the side effects and complications. This case report presents a female with atrophic scar in both cheeks. The case aims to prove the combination of MSCs and aqueous human placenta extract contained bioactive therapeutic molecules obviously promoted the improvement of skin scar to reach the optimal outcomes.

\section{Case Report}

A 35-year-old female presented with atrophic acne scar distributed on both cheeks. She had severe acne when she was adolescent, lead to atrophic scar in both cheeks. She volunteered and gave her written informed consent for this study. On physical examination, there were icepick, box, and rolling acne scar distribute overall both cheeks. Facial skin presented loose, flaccidity, and sagging. She had one e-matrix laser treatment for 1 week ago.

A diagnosis is an atrophic scar from severe acne vulgaris. She was healthy and routine laboratory investigations were normal. Management of this case is 10 million cells of commercialized umbilical cord mesenchymal stem cell combination with the human placenta extract (Life Balance Methodology Co., Ltd., Bangkok, Thailand). Pre-medication is dexamethasone $4 \mathrm{mg}$ intravenous injec- 
tion and topical anesthesia was applied to the face for 30 minutes before injection. Face skin was cleaned with $0.9 \%$ normal saline and chohexidine $70 \%$ used to disinfect before injection. MSCs-containing $\mathrm{RGF}^{\circledR}$ (human placenta extract) injected intradermal and subcutaneous, using 27-gauge needle. Under each scar $0.1-0.3 \mathrm{ml}$ was intradermally inject. After each injection, slightly cold compresses were done without massage. The observation and image capture were done at $0,3,14$, and 25 days. During treatment, there was not any cosmetics or drugs facial skin treatment.

After allogeneic MSC-contained $\mathrm{RGF}^{\circledR}$ injection, reduction of atrophic scar was observed in both cheeks. The number of all types of scar; icepick scar, box scar, and rolling scar were significant reduced at day 25 (Figures 1-3 and Table 1). Skin was significant lightened and brighten (Figure 1). After combination treatment, the improvement of atrophic scar, skin sagging and flaccidity was observed and increase complexity and elasticity of skin at day within day 14 (Figures 1-3). The wrinkle under both eyes was disappeared. The skin elasticity showed improvement after treatment to $80 \%$. The skin was dramatically hydrated and finer skin structure within 14 days after treatment. Icepick, box and rolling scar were significant reduction in single treatment within one 14 days. Skin scar was reduced and firmness. The qualitative scarring grading system and Cardiff acne disability index showed improving the atrophic acne scar and quality of life (Table 1 and Table 2). The results of 6 months follow up were interesting, scar improvement, texture, pore and skin complexity at least $80 \%$ and score improvement.
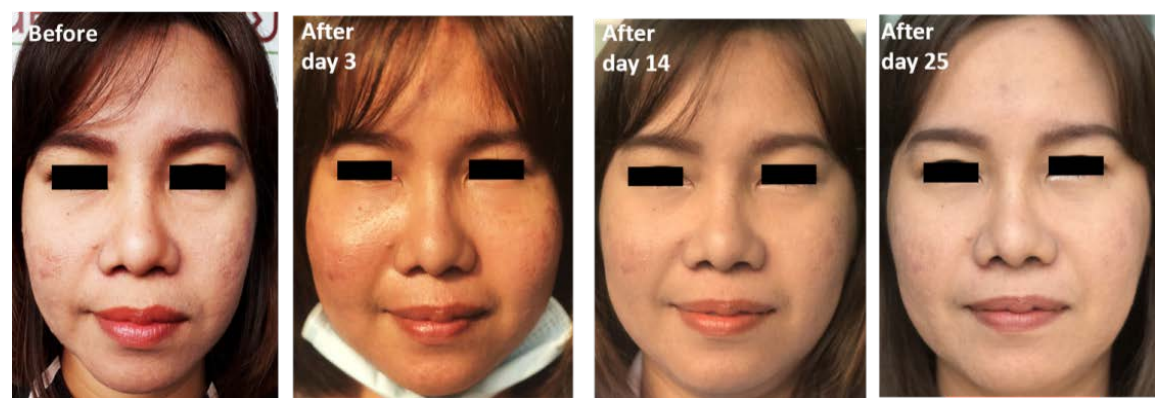

Figure 1. After MSC-contained $\mathrm{RGF}^{\circledR}$ solution injection improves atrophic acne scar, skin complexity and elasticity within day 25 .
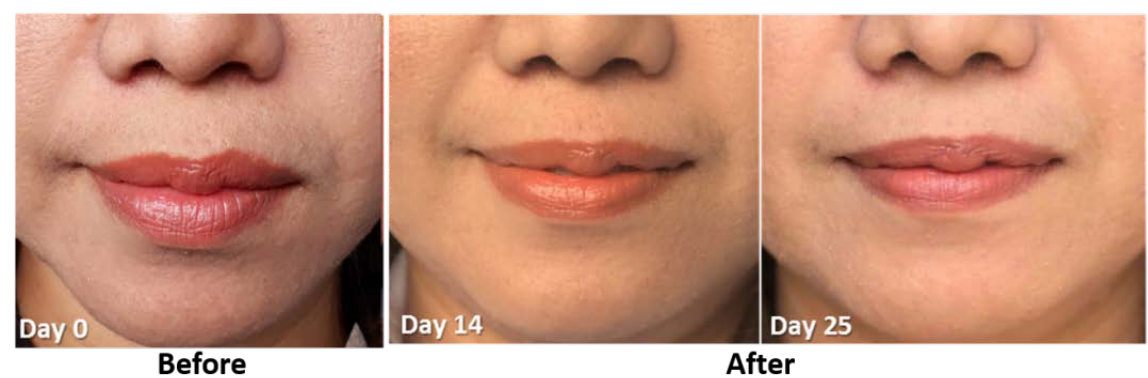

Figure 2. After MSCs-contained $\mathrm{RGF}^{\circledR}$ solution injection, improves sagging and flaccidity of skin and complexity and elasticity of skin within day 14 and 25 . 

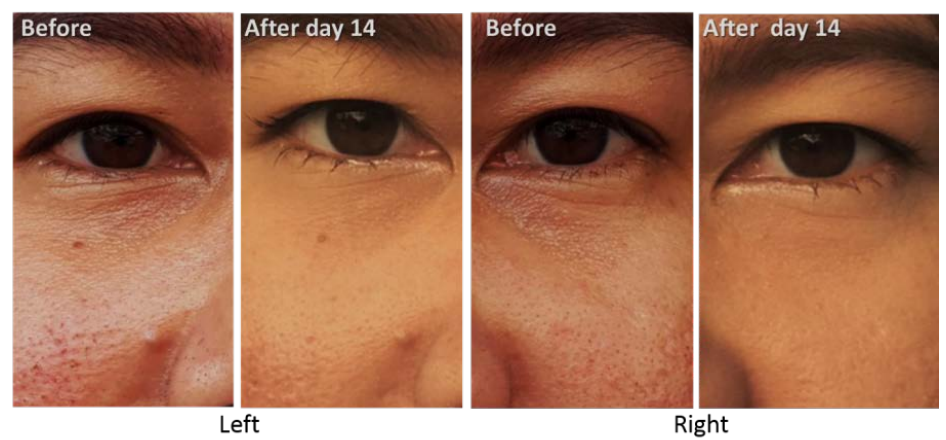

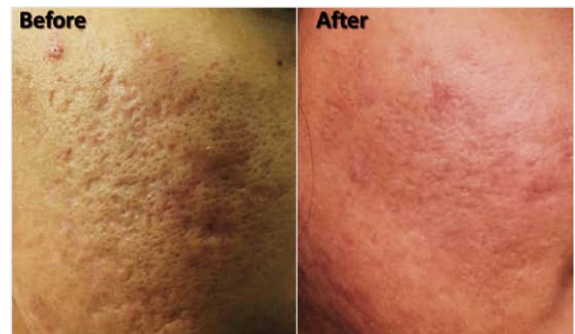

Left Cheek

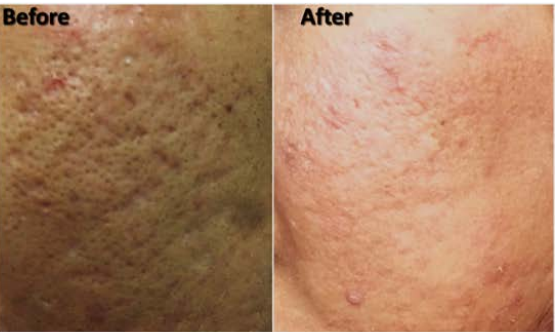

Right Cheek

Figure 3. After day 14 of MSCs-contained $\mathrm{RGF}^{\circledR}$ solution injection, atrophic acne scar was reduced and wrinkle around the eyes was disappeared and skin rejuvenation within day 14.

Table 1. Differential count of acne scar type's assessment before and after MSCs plus $\mathrm{RGF}^{\circledR}$ mesotherapy.

\begin{tabular}{ccc}
\hline Atrophic acne scar count & Before treatment & After treatment \\
\hline Icepick scars & 76 & 32 \\
Box scars & 45 & 12 \\
Rolling scars & 38 & 9 \\
\hline
\end{tabular}

Table 2. The assessment parameter before and after MSCs plus RGF $^{\circledR}$ mesotherapy.

\begin{tabular}{ccc}
\hline Assessment parameters & Before treatment & After treatment \\
\hline Qualitative scaring grading & 3 (moderate) & 2 (mild) \\
Cardiff acne disability index & 12 & 4 \\
\hline
\end{tabular}

\section{Discussion}

In this case study, we first found that allogeneic mesenchymal stem cell-contained placenta extract solution mesotherapy gave moderate to the high improvement of atrophic acne scar, skin complexity, and rejuvenation. After treatment with MSCs combined with human placenta extract suspension, the case shown $80 \%$ improvement of acne scar and skin complexity. The appearance of icepick, box and rolling scar was improved and skin texture looked fine and smoother. The results are similar to atrophic cutaneous lieshmaniasis, a mixture of 20 million fibroblasts in $1 \mathrm{ml}$ serum was injected beneath the scar are with $100 \%$ improvement. After 2 months, fibroblast suspension was injected again. The appearance of scar was improved in 3 months [19]. Mesenchymal stem cells are a great the- 
rapeutic value for cell-based therapy and tissue regeneration [16]. The main underlying mechanism for MSCs' beneficial effects in tissue regeneration is based on their capability to produce a large variety of bioactive trophic factors that stimulate neighboring parenchymal cells to start repairing damaged tissues. These bioactive factors modulate the local immune system, enhancing angiogenesis, preventing cell apoptosis, and stimulating survival, proliferation, and differentiation of resident tissue-specific cells [17].

MSCs secrete trophic factors such as vascular endothelial growth factor (VEGF), fibroblast growth factor (FGF), epidermal growth factor (EGF), and others, and growth factors promote cell regeneration and repair [7] [18], whereas the placenta extract promotes survival and proliferation of transplanted MSCs [20]. MSCs-placenta extract injection following intradermal subcision, MSCs fill the atrophic scar and human placenta extract promotes MSCs and resident cells in skin layer; fibroblast, keratinocytes, epithelial cells, and adipocyte proliferation and differentiation [21]. The combination treatment increases the density of cell in skin layer resulting in improving the skin complexity and elasticity. It also increases angiogenesis resulting in increased blood circulation. MSCs have multi-lineage potential differentiation and paracrine function. Placenta extract promotes survival and proliferation of MSCs during the early stage after seeding on the skin [22]. MSC-contained placenta extract solution injection is a safe, highly effective, and long-lasting method for skin rejuvenation [14]. The combination treatment had a higher satisfaction rate. Neither treatment caused any complications such as infection, anaphylaxis, or paresthesia during follow-up. In case of MSCs and placenta extract exhibits remarkable cosmetic efficacy in treating the atrophic scar and skin disorder [14] [22]. The effect of MSCs and human placenta extract have been associated with activating fibroblast proliferation and collagen synthesis via induction of fibroblast, improve the skin hydration and soft tissue augmentation [22] [23] [24]. Allogeneic umbilical cord mesenchymal stem cell and human placenta extract combined intradermal subcision and laser treatment are effective to improve all types of atrophic acne scar [22]. The stem cells and its placenta extracts exert a permanent effect on skin cells renewal and substitution scar tissue. It is safe and no severe adverse effect. It is a short downtime and speedy recovery. However, the limitation of the case study was a small sample size and short term follow up.

\section{Conclusion}

Mesenchymal stem cell (MSC) is a scientific approval for surgery scar treatment and wound healing. The combination of MSCs and aqueous human placenta extract $\left(\mathrm{RGF}^{\circledR}\right)$ contained bioactive therapeutic molecules obviously promoted the improvement of skin scar to reach the optimal outcomes. Here, the combination of MSC-contained human placenta extract solution subcision improved the atrophic acne scar and skin complexity by the enhancement of skin cell regeneration. 


\section{Acknowledgements}

This work was supported by Suranaree University of Technology (SUT) Research and Development Fund, and by the Office of the Higher Education Commission under the NRU Project of Thailand. The stem cells and placenta extract were provided from LBM Stem Cell Research Unit, Life Balance Methodology Co., Ltd., Bangkok, Thailand.

\section{Conflicts of Interest}

The authors declare no conflicts of interest regarding the publication of this paper.

\section{References}

[1] Connolly, D., Vu, H.L., Mariwalla, K., et al. (2017) Acne Scarring-Pathogenesis, Evaluation, and Treatment Options. The Journal of Clinical and Aesthetic Dermatology, 10, 12-23.

[2] Capitanio, B., Sinagra, J.L., Bordignon, V., et al. (2010) Underestimated Clinical Features of Postadolescent Acne. Journal of the American Academy of Dermatology, 63, 782-788. https://doi.org/10.1016/j.jaad.2009.11.021

[3] Basta-Juzbasic, A. (2010) Current Therapeutic Approach to Acne Scars. Acta Dermatovenerologica Croatica, 18, 171-175.

[4] Goodman, G.J. and Baron, J.A. (2006) Postacne Scarring: A Quantitative Global Scarring Grading System. Journal of Cosmetic Dermatology, 5, 48-52. https://doi.org/10.1111/j.1473-2165.2006.00222.x

[5] Lanci, A., Merlo, B., Mariella, J., et al. (2019) Heterologous Wharton's Jelly Derived Mesenchymal Stem Cells Application on a Large Chronic Skin Wound in a 6-Month-Old Filly. Frontiers in Veterinary Science, 6, 9. https://doi.org/10.3389/fvets.2019.00009

[6] Nakagawa, H., Akita, S., Fukui, M., et al. (2005) Human Mesenchymal Stem Cells Successfully Improve Skin-Substitute Wound Healing. British Journal of Dermatology, 153, 29-36. https://doi.org/10.1111/j.1365-2133.2005.06554.X

[7] Fu, Y., Karbaat, L., Wu, L., et al. (2017) Trophic Effects of Mesenchymal Stem Cells in Tissue Regeneration. Tissue Engineering Part B: Reviews, 23, 515-528. https://doi.org/10.1089/ten.teb.2016.0365

[8] Bhargava, S., Cunha, P.R., Lee, J., et al. (2018) Acne Scarring Management: Systematic Review and Evaluation of the Evidence. American Journal of Clinical Dermatology, 19, 459-477. https://doi.org/10.1007/s40257-018-0358-5

[9] Thiboutot, D.M., Dreno, B., Abanmi, A., et al. (2018) Practical Management of Acne for Clinicians: An International Consensus from the Global Alliance to Improve Outcomes in Acne. Journal of the American Academy of Dermatology, 78, S1-S23e1. https://doi.org/10.1016/j.jaad.2017.09.078

[10] Ibrahim, Z.A., Eltatawy, R.A., Ghaly, N.R., et al. (2015) Autologus Bone Marrow Stem Cells in Atrophic Acne Scars: A Pilot Study. Journal of Dermatological Treatment, 26, 260-265. https://doi.org/10.3109/09546634.2014.946379

[11] Neri, S. (2019) Genetic Stability of Mesenchymal Stromal Cells for Regenerative Medicine Applications: A Fundamental Biosafety Aspect. International Journal of Molecular Sciences, 20, pii: E2406. https://doi.org/10.3390/ijms20102406 
[12] Togashi, S., Takahashi, N., Iwama, M., et al. (2002) Antioxidative Collagen-Derived Peptides in Human-Placenta Extract. Placenta, 23, 497-502. https://doi.org/10.1053/plac.2002.0833

[13] Chakraborty, P.D., De, D., Bandyopadhyay, S., et al. (2009) Human Aqueous Placental Extract as a Wound Healer. Journal of Wound Care, 18, 462, 464-467. https://doi.org/10.12968/jowc.2009.18.11.44987

[14] Nair, B., Elmore, A.R. and Cosmetic Ingredient Review Expert Panel (2002) Final Report on the Safety Assessment of Human Placental Protein, Hydrolyzed Human Placental Protein, Human Placental Enzymes, Human Placental Lipids, Human Umbilical Extract, Placental Protein, Hydrolyzed Placental Protein, Placental Enzymes, Placental Lipids, and Umbilical Extract. International Journal of Toxicology, 21, 81-91. https://doi.org/10.1080/10915810290096405

[15] Shapira, I., Fainstein, N., Tsirlin, M., et al. (2017) Placental Stromal Cell Therapy for Experimental Autoimmune Encephalomyelitis: The Role of Route of Cell Delivery. Stem Cells Translational Medicine, 6, 1286-1294. https://doi.org/10.5966/sctm.2015-0363

[16] Najar, M., Bouhtit, F., Melki, R., et al. (2019) Mesenchymal Stromal Cell-Based Therapy: New Perspectives and Challenges. Journal of Clinical Medicine, 8, pii: E626. https://doi.org/10.3390/jcm8050626

[17] Kamolz, L.P., Keck, M. and Kasper, C. (2014) Wharton's Jelly Mesenchymal Stem Cells Promote Wound Healing and Tissue Regeneration. Stem Cell Research \& Therapy, 5, 62. https://doi.org/10.1186/scrt451

[18] Arno, A.I., Amini-Nik, S., Blit, P.H., et al. (2014) Human Wharton's Jelly Mesenchymal Stem Cells Promote Skin Wound Healing through Paracrine Signaling. Stem Cell Research \& Therapy, 5, 28. https://doi.org/10.1186/scrt417

[19] Nilforroushzadeh, M.A., Nasr Esfahani, M.H., Fesharaki, M.A., Siadat, A.H., Ansari, N. and Baradaran, E.H. (2010) Treatment of Atrophic Cutaneous Leishmaniasis Scar Using Autologous Fibroblasts and Keratinocytes. Journal of Research in Medical Science, 15, 125-126.

[20] Saud, B., Malla, R. and Shrestha, K. (2019) A Review on the Effect of Plant Extract on Mesenchymal Stem Cell Proliferation and Differentiation. Stem Cells International, 2019, Article ID: 7513404. https://doi.org/10.1155/2019/7513404

[21] Fathke, C., Wilson, L., Hutter, J., et al. (2004) Contribution of Bone Marrow-Derived Cells to Skin: Collagen Deposition and Wound Repair. Stem Cells, 22, 812-822. https://doi.org/10.1634/stemcells.22-5-812

[22] Golchin, A., Farahany, T.Z., Khojasteh, A., et al. (2019) The Clinical Trials of Mesenchymal Stem Cell Therapy in Skin Diseases: An Update and Concise Review. Current Stem Cell Research \& Therapy, 14, 22-33. https://doi.org/10.2174/1574888X13666180913123424

[23] Hong, J.W., Lee, W.J., Hahn, S.B., et al. (2010) The Effect of Human Placenta Extract in a Wound Healing Model. Annals of Plastic Surgery, 65, 96-100. https://doi.org/10.1097/SAP.0b013e3181b0bb67

[24] Berebichez-Fridman, R. and Montero-Olvera, P.R. (2018) Sources and Clinical Applications of Mesenchymal Stem Cells: State-of-the-Art Review. Sultan Qaboos University Medical Journal, 18, e264-e277. https://doi.org/10.18295/squmj.2018.18.03.002 